\title{
Da Coisa impossível ao desejo da mãe interditada
}

\author{
Evandro de Quadros Cherer' \\ Universidade de Brasília, Brasília, DF, Brasil \\ Daniela Scheinkman Chatelard \\ Universidade de Brasília, Brasília, DF, Brasil
}

\begin{abstract}
Resumo: Este estudo teórico em psicanálise visa elaborar uma aproximação conceitual da mãe enquanto objeto interditado/desejado à noção de das Ding. Foi realizada uma pesquisa por meio de textos, especialmente da obra freudiana, que abordassem esse tema, os quais também foram cotejados com algumas considerações produzidas por Lacan. A partir da perspectiva da falta de objeto, abordou-se a interdição e o desejo pela mãe como referente à inacessibilidade de das Ding, isto é, relativo ao primeiro objeto mítico de satisfação. Com isso, ainda que a mãe corresponda a uma coisa (die Sache), ela possui valor enquanto das Ding ao ser interditada e desejada. Desse modo, a interdição da mãe pode ser pensada como referente à impossibilidade de acesso à Coisa. Essa tensão evidencia a articulação entre lei e desejo, aspecto central para se pensar a importância da interdição do incesto.
\end{abstract}

Palavras-chave: Complexo de Édipo; desejo; interdição; mãe; psicanálise.

\section{FROM THE IMPOSSIBLE THING TO THE DESIRE OF THE FORBIDDEN MOTHER}

\begin{abstract}
This theoretical study in psychoanalysis aims at developing a conceptual approach of the mother as an interdicted/desired object to the idea of das Ding. We conducted the research based on some texts, especially the Freudian work on this subject, but also taking into consideration studies by Lacan. The perspective of the lack of object considers the interdiction of incest as a reference to the inaccessibility of the first mythical object of satisfaction (das Ding). Even if the mother is one thing (die Sache), in the interdiction, she has value as das Ding. Thus, the interdiction of incest can be a reference to the impossibility of accessing the Thing. This tension reveals the relationship between law and desire, showing the importance of the interdiction of incest.
\end{abstract}

Keywords: Oedipus Complex; desire; interdiction of incest; mother; psychoanalysis.

\section{DE LA COSA IMPOSIBLE AL DESEO DE LA MADRE PROHIBIDA}

Resumen: Este estudio teórico en psicoanálisis tiene como objetivo desarrollar un enfoque conceptual de la madre como objeto prohibido/deseado a la noción de das Ding. Se realizó un estudio por medio de algunos textos, en especial de los trabajos de Freud que abordaron este tema, que también se compara con algunas consideraciones producidos por Lacan. Desde la perspectiva de la falta de objeto, se entendió que la

1 Endereço de correspondência: Universidade de Brasília, Instituto de Psicologia, Departamento de Psicologia Clínica e Cultura. Campus Universitário Darcy Ribeiro, ICC - Ala Sul, Bloco A, Térreo. CEP: 70910-900 - Brasília, DF. E-mail: quadroscherer@gmail.com 
interdicción del incesto es una referencia a la inaccesibilidad del primer objeto mítico de satisfacción (das Ding). Por lo tanto, incluso si la madre es una cosa (die Sache), ella tiene valor como das Ding a ser prohibido. Por lo tanto, la prohibición del incesto puede ser pensado como una referencia a la imposibilidad de acceso a la Cosa. Esta tensión, que muestra la relación entre la ley y el deseo, es fundamental para pensar la importancia de la prohibición del incesto.

Palabras clave: Complejo de Edipo; deseo; interdicción; madre; psicoanálisis.

\section{Introdução}

Das muitas questões analisadas pela psicanálise, a interdição da mãe sobressai-se como um dos elementos essenciais do pensamento freudiano. Essencialmente na elaboração do Complexo de Édipo e em Totem e Tabu, Freud formulou que a mãe é interditada ao filho pelo pai, fato que convoca a criança a se haver com a lei paterna que proíbe o seu objeto de desejo. Tendo em vista o valor teórico crucial dessa questão, assim como dos desdobramentos teóricos e clínicos advindos desses aspectos, este estudo visa elaborar uma aproximação conceitual da mãe enquanto objeto barrado no incesto à noção de das Ding. Trata-se, portanto, de um estudo teórico em psicanálise com o intuito de sustentar que, ainda que a mãe corresponda a uma coisa (die Sache), ela possui valor enquanto das Ding ao ser interditada. A partir da perspectiva da falta de objeto, a interdição do incesto é associada neste estudo à inacessibilidade de das Ding, isto é, relativo ao primeiro objeto mítico de satisfação. Sendo assim, a interdição do incesto pode ser redimensionada como referente à impossibilidade de acesso à Coisa. Para tanto, este artigo elencou alguns textos freudianos que dizem respeito à mãe enquanto objeto interditado/desejado, os quais foram cotejados com algumas considerações produzidas por Lacan.

Uma das questões problematizadas por Freud (1930/2012), em seu trabalho "O mal-estar na cultura", foi a finalidade da vida humana. Para ele, esse questionamento apenas encontraria resposta na religião, então, tal questão foi deixada em suspenso. Diante disso, Freud passou para o que considerou ser uma pergunta mais modesta: 0 que o ser humano quer da vida? Para ele, essa resposta é difícil de errar, pois as pessoas desejam a felicidade, ou seja, querem ser e permanecer felizes. Conforme Freud (1930/2012), essa aspiração pode ocorrer de dois modos, a saber: evitando-se o desprazer ou ainda tendo experiências de sensações intensas de prazer. Além disso, na perspectiva freudiana, em sentido mais restrito, a felicidade estaria vinculada à essa última forma, isto é, às intensas satisfações advindas de contrastes. Entretanto, para Freud (1930/2012), a vida em cultura impõe ao humano a renúncia de parte desse modo de satisfação. $O$ ser humano é convocado a renunciar parcialmente às próprias satisfações pulsionais mais intensas, limitando, desse modo, a sua felicidade plena. Freud (1930/2012) teria levado isso até as últimas consequências, acreditando que o sofrimento seria algo muito mais certo para o humano do que a felicidade: "seria possível dizer que o propósito de que o homem seja 'feliz' não faz parte do plano da 'Criação'" (Freud, 1930/2012, p. 63). Restaria a cada um se deparar com os sofrimentos ameaçadores 
provenientes principalmente de três fontes, a saber: o corpo, o mundo externo e, talvez o mais doloroso, as relações com outras pessoas.

Esses aspectos permearam todo o pensamento freudiano, sendo um dos conteúdos mais frequentes e debatidos em psicanálise aquele que diz respeito à interdição vivenciada pelo ser falante. Desde o "Rascunho N", Freud (1897/1990) já havia abordado a interdição como uma renúncia para a formação da cultura. Posteriormente, Freud (1908/1990) permaneceu abordando o sofrimento decorrido devido aos limites pulsionais impostos pelo convívio social. Para ele, a cultura se constitui a partir de renúncias pulsionais, exigindo que cada um ceda de uma parcela de suas inclinações agressivas, bem como de uma plenitude almejada. Com isso, constata-se que, desde os escritos iniciais, as elaborações freudianas demarcaram existir um antagonismo entre vida pulsional e laço social, arranjo que exige uma renúncia.

\section{Desenvolvimento}

Particularmente em sua teorização do Complexo de Édipo, Freud (1924/1990) formulou que a mãe seria o objeto interditado/desejado a todos. No caso do menino, ele considerou que ele procuraria ter a mãe como sua propriedade. No entanto, essa possessão seria interditada por meio da invocação do pai ou de alguém que ocuparia uma posição paterna. A percepção da diferença anatômica entre os sexos colocaria em cena que o menino poderia ser castrado pelo próprio pai, o qual possuiria por direito a mãe. Seria a ameaça de castração que colocaria certo fim a essa trama, podendo-se pensar que é pela impossibilidade do Complexo de Édipo que este acabaria por fracassar. No caso da menina, a mãe também foi proposta como o primeiro objeto de desejo. Entretanto, seria a constatação da diferença anatômica que a conduziria ao Complexo de Édipo e, por conseguinte, à mudança de objeto de amor da mãe para o pai. Em um de seus últimos escritos, Freud (1940 [1938]/1990) permaneceu compreendendo que todas as crianças estariam destinadas a passar pelo Complexo de Édipo devido ao prolongado período de criação e convivência com seus progenitores. A cena de amamentação foi utilizada como modelo da satisfação, a partir da qual a criança estabeleceria sua primeira relação erótica com um objeto, no caso, o seio materno. Esse primeiro objeto erótico seria, posteriormente, completado na mãe como um todo, a qual, mais do que apenas alimentar seu filho, também cuida dele. Essas ações maternas na criança provocariam sensações corporais que a tornariam a primeira sedutora, protótipo a partir do qual reside o modelo freudiano do primeiro objeto de amor para ambos os sexos.

Esses aspectos também podem ser observados em Totem e Tabu. A proposta freudiana de comparação entre povos nomeadamente "primitivos" e a vida psíquica do neurótico se baseou no entendimento de que a primeira escolha objetal do menino é incestuosa, referindo-se à mãe, ao ponto de Freud (1913/2013) ter formulado que o complexo nuclear da neurose é dominado pelos desejos incestuosos pelos pais. Desse modo, a recusa aos desejos incestuosos submetidos ao recalque se manifestaria pela 
extrema aversão ao incesto, revelando, com isso, traços eminentemente infantis presentes nesse horror. Nesse contexto, Freud (1913/2013) criou o mito de que em certa época existiria um pai ciumento que manteria todas as mulheres para si e agiria de forma violenta, expulsando seus filhos quando eles crescessem. Esse grupo de irmãos, assim como as crianças e os neuróticos, seriam possuídos por sentimentos ambivalentes em relação ao pai. Ao mesmo tempo que amavam o pai, eles o odiavam por ser o empecilho aos seus desejos sexuais. Porém, certo dia, os irmãos que haviam sido expulsos uniram-se e resolveram dar um fim à horda paterna, realizando aquilo que seria impossível de se efetuar individualmente. Eles se reuniram e mataram o pai, devorando-o após o seu homicídio. O pai, que outrora era temido e invejado, serviria de modelo para os filhos. Assim, ao devorá-lo, os irmãos se identificaram com ele, apropriando-se de parte de seus atributos.

No entanto, depois de comê-lo e de realizarem o desejo de eliminá-lo e de se identificarem com ele, os sentimentos ternos se impuseram por meio de arrependimento e de culpa. Ainda que o pai tivesse sido eliminado quando os irmãos se aliaram, eles ainda nutriam o desejo de ser como o pai e de tomarem todas as mulheres para si, assim cada irmão era rival um do outro. Todavia, "não havia nenhum indivíduo de força superior que pudesse assumir o papel do pai com sucesso" (Freud, 1913/2013, p. 210). Diante disso, foi assegurado que nenhum deles seria tratado como o pai, impossibilitando novamente o destino paterno. Ninguém poderia, nem teria permissão para obter a almejada plenitude de poderes do pai. Todos os irmãos continuaram privando-se do objeto de seu desejo, renunciando às mulheres e tornando ilícita a morte do substituto do pai, a saber, o totem. O que antes era interditado pelo pai passou a ser proibido pelos próprios filhos numa obediência a posteriori, e com isso "O morto se tornou mais forte do que o vivo tinha sido" (Freud, 1913/2013, p. 209). A partir disso, eles preservaram a organização social formada, sustentando-a na cumplicidade do parricídio praticado por todos.

Essa obra sofreu diversas críticas após sua publicação, sendo, evidentemente, muitas vezes questionável o raciocínio antropológico desenvolvido nessa elaboração, bem como em sua falta de evidências empíricas. Entretanto, Lacan (1959-1960/2011) propôs que essa obra não fosse lida enquanto uma narrativa histórica, mas como um mito moderno. Dessa forma, é possível pensar que a relevância de Totem e Tabu não se encontra em seu possível caráter etnográfico ou antropológico. A utilização de dados de diversos povos, bem como a criação do mito da horda primeva podem ser pensados como uma ficção freudiana.

Com esse mito sobre a horda primeva, Freud (1913/2013) criou seu protótipo sobre a origem cultural, abordando a interdição do objeto de desejo, do qual apenas o pai morto havia desfrutado. Esse drama primordial evidencia que o assassinato do pai está na origem da cultura. O personagem onipotente que seria obstáculo foi eliminado e mesmo assim as mulheres não deixaram de continuar interditadas, mas, mais do que isso, essa interdição foi reforçada: "o assassinato do pai não abre a via para o gozo 
que sua presença era suposta interditar, mas ele reforça sua interdição" (Lacan, 19591960/2011, p. 211). Salienta-se também que os irmãos optaram por absterem-se de ser como o pai, preservando a formação social instituída entre eles. Com isso, Freud (1913/2013) demarcou a imprescindibilidade da renúncia pulsional para a própria constituição do sujeito na cultura.

Antes de se prosseguir com a discussão sobre a mãe enquanto objeto interditado/ desejado, compreendeu-se ser essencial abordar um aspecto que permeará toda a leitura dos demais assuntos aqui tratados: a falta de objeto. A respeito disso, articulando-se a série prazer-desprazer tratada em O mal-estar na cultura, Freud (1915/2004) já havia concebido o conceito de pulsão como uma força constante que sempre possui como meta a satisfação. Para tratar esse assunto, desde o "Projeto para uma psicologia" (1895/1986), a perspectiva freudiana sustentou-se na primeira experiência de satisfação, que ocorreria quando um estímulo endógeno sofresse descarga por meio de uma ação específica, a qual, todavia, não poderia ser executada solitariamente. Desse modo, seria necessário um auxílio externo, que foi descrito por Freud (1895/1986) como advindo de uma alteridade que executa essa ação específica diante do desamparo inicial do ser humano. Por meio dessa situação, o estímulo endógeno seria cancelado, sofrendo descarga. A partir disso, com o reaparecimento do estado de desejo, se seguiria uma atração para o objeto de desejo, sendo, a rigor, uma atração para o traço mnêmico deixado por esse objeto, o qual teria formado um trilhamento que funcionaria como uma via facilitadora.

Depreende-se disso que o humano, em seu estado de desamparo inicial, precisou de uma alteridade a fim de conter o excesso tensional que ameaçava o aparelho psíquico. A partir dessa ação específica, para além de um ser de pura necessidade, o humano adquire uma vida pulsional atrelada a esse primeiro objeto. Todavia, como salientou Lacan (1959-1960/2011), esse objeto não nos é nem mesmo dito. Ele deve ser reencontrado, supondo-se, pois, perdido. Esse objeto da primeira satisfação, a Coisa, assim nomeada por Freud (1895/1986) em "Projeto para uma psicologia", apresenta-se no escrito original em alemão como "das Ding", com o uso do artigo neutro "das". Há duas possibilidades na língua alemã para se dizer "a coisa": "die Sache" ou "das Ding". Enquanto a primeira forma emprega o artigo definido feminino "die", na segunda opção usa-se o artigo neutro "das". Em todas as ocasiões, nesta obra, Freud empregou "die Sache", excetuando-se para se referir ao primeiro objeto. Há, portanto, uma distinção entre das Ding e die Sache, ou seja, entre a Coisa da primeira experiência de satisfação e todas as demais coisas.

Em "A interpretação dos sonhos", utilizando-se da cena de amamentação, Freud (1900/2012a) descreveu que o bebê faminto chora e se movimenta, sem, contudo, conseguir alterar a situação. Só pode haver uma mudança quando, por meio de um auxílio externo, cancela-se o estímulo interno, alcançando-se, assim, a experiência de satisfação. Além disso, a imagem mnêmica dessa experiência ficaria associada ao traço da excitação. Com isso, na próxima vez que o estímulo interno surgir, a moção psíquica 
será guiada para investir novamente a imagem mnêmica, procurando restabelecer a situação da primeira experiência na qual se supõe ter ocorrido uma satisfação plena, sendo essa moção nomeada de desejo. A respeito disso, Freud (1900/2012) também demarcou o caráter atemporal e indestrutível desses processos inconscientes, revelando com isso que, em psicanálise, este sempre é um desejo inconsciente, relacionado à sexualidade infantil recalcada, cujas implicações não podem ser esquivadas. Portanto, na perspectiva freudiana, é o desejo que moveria o aparelho psíquico.

Considerando esses aspectos, Lacan (1956-1957/1995) situou que o problema próprio do humano está nessa nostalgia em relação ao objeto referente ao primeiro desmame e às satisfações iniciais. Trata-se, pois, de uma repetição impossível, uma vez que nunca será o mesmo objeto, não haveria como sê-lo. É a partir da procura de uma satisfação passada e ultrapassada que outros objetos são procurados. Desse modo, evidencia-se a noção freudiana de que, por mais que a meta pulsional seja sempre encontrar a satisfação, o caminho para atingir esse objetivo pode ser diverso. É nesse sentido que Freud (1915/2004) demarcou que o meio pelo qual essa meta seria alcançada é o que há de mais variável, evidenciando, assim, o caráter problemático do objeto da pulsão, visto que o reencontro com a Coisa (das Ding) é marcado por ser impossível. A partir disso, pode-se perceber um hiato impossível de ser superado entre o objeto mítico da primeira experiência de satisfação e as tentativas de reencontrá-lo em objetos parciais, constituindo, desse modo, uma distância intransponível, isto é, o próprio desejo.

Nessa perspectiva, retomando a cena mítica da primeira experiência de satisfação, a qual, na obra freudiana, foi ilustrada por meio da relação mãe-criança, pode-se entender que "tudo o que se desenvolve no nível da interpsicologia criança-mãe [...] não é senão um imenso desenvolvimento da coisa materna, da mãe na medida em que ela ocupa o lugar dessa coisa, de das Ding" (Lacan, 1959-1960/2011, p. 84). Ainda que a mãe não seja o correlato exato de das Ding, pode-se considerar que ela ocupa esse lugar para o filho, mesmo que, a rigor, ela seja a coisa, isto é, die Sache. Com efeito, o que é desejado na mãe é das Ding, ainda que a Coisa de fato seja intangível de ser, na medida em que, como definiu Lacan (1959-1960/2011), essa se situa fora-do-significado, mas, todavia, orienta o trilhamento das representações.

Ao encontro dessas ideias, em "Um tipo especial de escolha de objeto feita pelos homens", Freud (1910/1990) já havia elencado condições que na neurose seriam exigidas do objeto amoroso. Para explicar esses aspectos, pela primeira vez empregou a expressão "Complexo de Édipo", relacionando a isso o protótipo materno de escolha objetal. De forma equivalente ao complexo, o homem buscaria um objeto amoroso no qual encontraria um rival, semelhante ao que seu pai havia sido em relação à mãe. Parte da essência desse protótipo materno repousaria na condição de que o objeto amado pertenceria a outrem, isto é, existe algo que impede a acessibilidade ao que se deseja. Esse objeto também deveria ter uma má reputação como uma prostituta, respondendo à fantasia infantil de que a mãe trairia o pai com o menino. Por fim, a última das três condições elencadas por Freud (1910/1990) é referente ao homem que 
procuraria salvar o objeto amoroso, aspecto relacionado a conceder um filho à mãe como forma de pagar a dívida da vida. Sendo assim, esse modelo possui como fator determinante que todos os demais objetos pertencem a uma série infindável de substitutos maternos. Esses, no entanto, são incapazes de alcançar a satisfação almejada, visto que não são objeto da primeira satisfação, o qual, todavia, foi interditado.

Como visto, a mãe em psicanálise é apresentada como o objeto de desejo infantil. É a partir desse modelo que os demais objetos poderão constituir uma cadeia infindável de substitutos, visto que a criança é impedida de ter a mãe para si. O pai, desse modo, surge como o rival que detém a mãe e barra a realização do desejo da criança. O incesto é então interditado para que o humano saia da relação exclusivamente materna e passe a se haver com sua condição de castrado. Desse estado de coisas, sustenta-se, neste estudo, que a interdição do incesto não está restrita à relação mãe-criança. É plausível considerar que a psicanálise fez uso da relação mãe-pai-criança a fim de, em alguma medida, abordar esse conceito, que pode ser entendido como uma teorização acerca da interdição do objeto de desejo. A respeito disso, para Lacan (1938/2008), é a mãe, como primeiro objeto das tendências pulsionais, como alimento e como seio, que se propõe inicialmente ao desejo edípico.

Nessa lógica, Lacan (1959-1960/2011) utilizou a epístola de Paulo aos romanos, que defende o não conhecimento do pecado senão pela lei: "Que diremos pois? É a lei pecado? De modo nenhum. Mas eu não conheci o pecado senão pela lei; porque eu não conheceria a concupiscência, se a lei não dissesse: Não cobiçarás" (Romanos 7:7). Há uma relação entre a proibição e o desejo, demarcando que não haveria pecado sem a lei. Assim, trocando a palavra "pecado" por "Coisa", Lacan (1959-1960/2011) evidenciou que a interdição do objeto está associada ao fato de esse ser desejado: "Eu não conheci a Coisa senão pela Lei. Porque não teria ideia de concupiscência se a Lei não dissesse - Não cobiçarás" (Lacan, 1959-1960/2011, p. 103). É devido ao fato de o pai ter a mãe para si e ela ser barrada ao filho que esta será desejada. Com isso, a mãe enquanto Coisa que é interditada se torna um objeto de desejo. Reafirmando esses aspectos, Lacan (1962-1963/2005, p. 93) proferiu:

O que Ihes ensino, aquilo a que os conduz o que lhes ensino, e que já está no texto, mascarado sob o mito de Édipo, é que esses termos, o desejo e a lei, que parecem colocar-se numa relação de antítese, são apenas uma e a mesma barreira, para nos barrar o acesso à Coisa.

Considerando que sempre é um objeto a ser reencontrado, o ser falante está condicionado a essa questão primordial. Com isso, a leitura de Lacan (1955-1956/2010) da teoria freudiana do mundo objetal implica numa suspensão no que constitui o objeto fundamental desejado pelo humano: "o sujeito não tem de encontrar o objeto de seu desejo [...] ele deve ao contrário reencontrar o objeto, cujo aparecimento é fundamentalmente alucinado. É claro, jamais o reencontra" (Lacan, 1955-1956/2010, p. 104, grifos do autor). Desse estado de coisas, compreende-se que a interdição barrando o acesso ao objeto é constitutiva ao humano, o qual, por meio dessa operação, torna-se 
desejante. Assim, é a própria interdição, ou seja, a lei que possibilita o surgimento do desejo, é a inacessibilidade da Coisa que determina o desejo pelo objeto proibido, evidenciando-se o valor dessa interdição. Desse modo, Lacan (1959-1960/2011) argumentou que o desejo pela mãe não pode ser satisfeito, tendo em vista que seria o término da demanda, ou seja, o que estrutura essa configuração desejante, a lei da interdição do incesto, uma vez que o ser humano busca algo inatingível. Certamente, esse desejo não corresponde à consumação de relações sexuais com a genitora. Ainda que alguém o faça, não é disso que se trata. Essa suposta satisfação plena do desejo absoluto diz respeito a esse para-além, lugar da Coisa inominável, que precisamente conserva o humano aquém, protegendo-o do término tensional. É essa barreira que protege o ser falante de uma excitação insuportável veiculada ao campo do desejo radical, uma vez que esse corresponde à destruição absoluta do aparelho psíquico.

\section{Conclusão}

Este estudo procurou elaborar uma aproximação conceitual da mãe enquanto objeto interditado/desejado à noção de das Ding. Evidenciou-se, por meio de alguns textos freudianos cotejados com algumas contribuições lacanianas, que o desejo, por estar relacionado à própria falta constitutiva, não está a serviço de uma harmonia absoluta, sendo impossível de ser sanado. A perspectiva freudiana revela um hiato intransponível existente entre a pulsão e o objeto, resistindo à possibilidade da satisfação plena do desejo. Há, portanto, uma relação com a pulsão que passa necessariamente pelos trilhamentos deixados por das Ding, de modo que certo nível de excitação não seja alcançado, demarcando uma impossibilidade.

A busca pelo momento em que se poderá estar completo está fadada ao fracasso, pois, como indica a experiência analítica, é inerente ao ser falante uma incompletude irremediável. Desvela-se disso, inclusive, toda uma sorte de implicações que demonstram não existir um direcionamento de qual objeto seria o mais adequado à satisfação sexual (Alves \& Almeida, 2017). É exatamente a promessa de vislumbrar continuamente num porvir a satisfação que impulsiona o aparelho psíquico, sendo por meio dos sucessivos substitutos que se tenta encontrar o objeto perdido. Todavia, essas tentativas resultam consecutivamente em contornar o vazio, uma vez que das Ding está sempre alhures (Jorge, 2000).

Entre as eventuais limitações deste estudo, podem-se considerar os impasses com a noção de das Ding, visto que não é um conceito conclusivo, impondo uma problemática densa que possui diversos desdobramentos teóricos e conceituais, os quais evidentemente não foram esgotados neste artigo. Ao encontro do que é próprio da psicanálise, não se produziu um estudo totalmente fechado. Ao contrário, acredita-se que muitas das noções discutidas remetem a tantas outras problemáticas que podem ser relidas de distintas maneiras, caso necessário. Cabe também destacar que as considerações teóricas foram feitas em referência à neurose, ocorrendo de maneira distinta em outras estruturas. De todo modo, pode-se observar o caráter estrutural de das Ding sustentado neste estudo, aspecto que conduz à constatação de que a Coisa não está à 
mercê de variações sócio-históricas, como as que dizem respeito às mudanças nas configurações familiares.

Apesar dos impasses impostos com a noção de das Ding, percebe-se um caráter essencial no pensamento psicanalítico. O único modo de se supor perdido das Ding é no só-depois desencadeado pela procura de seu reencontro. Também se pode pensar nesse conceito como uma realidade muda, que, apesar disso, organiza as coordenadas de prazer, constituindo, desse modo, um sistema de referência. Trata-se, pois, de algo que está no centro e simultaneamente excluído, orientando o encaminhamento subjetivo. Frente a isso, pode-se questionar se não seria exatamente esse o lugar da psicanálise, operar em torno desse vazio na construção da ficção do sujeito (Seganfredo \& Chatelard, 2014).

Considerando os aspectos apresentados, compreende-se que, devido à própria constituição, o humano está fadado a um reencontro impossível com o objeto, com a Coisa. Retomando as ideias de Freud (1930/2012) em O mal-estar na cultura, compreende-se a ideia freudiana de que, ao humano, a felicidade plena é barrada. Freud (1930/2012) concebeu que essa aspiração humana está em conflito com o mundo inteiro, sendo, de fato, totalmente irrealizável. Assim, para Freud (1930/2012), o propósito da felicidade não estaria contemplado no humano, na medida em que a própria constituição subjetiva barraria o acesso a ela.

Além disso, constatou-se que, relacionado a esses conceitos, articulam-se muitas elaborações cruciais em psicanálise, por exemplo, a relação do humano com algo primordial que de diversas maneiras foi tratado na relação mãe-pai-criança. Com isso, na perspectiva freudiana, existe uma proibição do objeto de desejo que na novela edípica é referente à mãe e, como visto, ao protótipo das demais escolhas objetais. Essa, no entanto, possui valor em sua relação com a Coisa, pois o que se encontra na lei do incesto situa-se como tal no nível da relação inconsciente com das Ding. É por ser interditado o desejo de tê-la que o humano buscará outros objetos, que poderão ser candidatos a fim de ocupar esse lugar. A abordagem lacaniana desvinculou a interdição a meros personagens, atribuindo ao mito de Édipo a associação entre desejo e lei. Enquanto proibida pela lei, nomeada de pai, que a mãe se torna desejada: "É na medida em que proíbe esse desejo que a lei impõe o desejá-la, pois, afinal, a mãe não é, em si mesma, o objeto mais desejável" (Lacan, 1962-1963/2005, p. 120). Trata-se, portanto, de uma relação bastante estreita, pois é a lei que traça o desejo. Se em alguma medida busca-se outra mulher no lugar da mãe, é na medida em que um mandamento foi introduzido na estrutura do desejo, isto é, deseja-se no mandamento.

\section{Referências}

Alves, R. B. \& Almeida, M. T. F. (2017). Da perda do objeto: o encontro sobre o abismo. Psicologia USP, 28(1), 102-107. doi:10.1590/0103-656420160007 
Freud, S. (1986) Proyecto de psicología. (J. Etcheverry, Trad.). In J. Strachey (Org.), Obras Completas (vol. 1, pp. 323-446). Buenos Aires: Amorrortu. (Original publicado em 1895).

Freud, S. (1990a). Carta 64. (J. Etcheverry, Trad.). In J. Strachey (Org.), Obras Completas (Vol. 1, pp. 295-299). Buenos Aires: Amorrortu. (Original publicado em 1897).

Freud, S. (1990b). El sepultamiento del complejo de Edipo. (J. Etcheverry, Trad.). In J. Strachey (Org.), Obras Completas (vol. 19, pp. 179-187). Buenos Aires: Amorrortu. (Original publicado em 1924).

Freud, S. (1990c). Esquema del psicoanálisis (J. Etcheverry, Trad.). In J. Strachey (Org.), Obras Completas (vol. 23, pp. 133-210). Buenos Aires: Amorrortu. (Original publicado em 1940 [1938]).

Freud, S. (1990d). La moral sexual "cultural" y la nerviosidad moderna. (J. Etcheverry, Trad.). In J. Strachey (Org.), Obras Completas (Vol. 1, pp. 159-181). Buenos Aires: Amorrortu. (Original publicado em 1908).

Freud, S. (1990e). Sobre un tipo particular de elección contribuciones a la psicología del amor (Contribuciones de la Psicología del amor, I). (J. Etcheverry, Trad.). In J. Strachey (Org.), Obras Completas (vol. 11, pp. 155-168). Buenos Aires: Amorrortu. (Original publicado em 1910).

Freud, S. (2004). Pulsões e destinos da pulsão. In Escritos sobre a psicologia do inconsciente. (Vol. 1, p.133-162). Rio de Janeiro: Imago. (Original publicado em 1915).

Freud, S. (2012a). A interpretação dos sonhos. (Zwick, R., Trad.). Porto Alegre: L\&PM. (Original publicado em 1900).

Freud, S. (2012b). O mal-estar na cultura. Porto Alegre: L\&PM. (Original publicado em 1930).

Freud, S. (2013). Totem e tabu: algumas correspondências entre a vida psíquica dos selvagens e a dos neuróticos. (Zwick, R., Trad.). Porto Alegre: L\&PM. (Original publicado em 1913).

Jorge, M. A. C. (2000). Fundamentos de psicanálise de Freud a Lacan (Vol. 1, $6^{\mathrm{a}}$ ed.). Rio de Janeiro: Jorge Zahar.

Lacan, J. (1995). O seminário, livro 4: a relação de objeto (1956-1957). Rio de Janeiro: Zahar. (Original publicado em 1957).

Lacan, J. (2005). O seminário, livro 10: a angústia. Rio de Janeiro: Zahar. (Original publicado em 1962-1963).

Lacan, J. (2008). Os complexos familiares na formação do indivíduo: ensaio de análise de uma função em psicologia. Rio de Janeiro: Zahar. (Original publicado em 1938). 
Lacan, J. (2010). O seminário, livro 3: as psicoses (1955-1956). Rio de Janeiro: Zahar. Lacan, J. (2011). O seminário, livro 7: a ética da psicanálise, 1959-60. Rio de Janeiro: Zahar. (Original publicado em 1959-1960).

Seganfredo, G. F. C. \& Chatelard, D. S. (2014). Das Ding: o mais primitivo dos êxtimos. Cadernos de Psicanálise, 36(30), 61-70.

Submissão: 1.10.2016 Aceite: 17.11.2017 